\title{
Retransplantation of the lung comes of age
}

\author{
Shaf Keshavjee, MD
}

See related article on page 407

From the Toronto Lung Transplant Program, University of Toronto, Toronto, Ontario, Canada.

Received for publication April 3, 2006; accepted for publication April 11, 2006.

Address for reprints: Shaf Keshavjee, MD, Director, Toronto Lung Transplant Program, Professor and Chair, Division of Thoracic Surgery, University of Toronto-Toronto General Hospital, 200 Elizabeth St, 9N-947, Toronto, Ontario M5G 2C4, Canada (Email: Shaf.Keshavjee@uhn.on.ca).

J Thorac Cardiovasc Surg 2006;132:226-8

$0022-5223 / \$ 32.00$

Copyright (๑) 2006 by The American Association for Thoracic Surgery

doi:10.1016/j.jtcvs.2006.04.005

$\mathrm{L}$ ung transplantation has entered a new era-serious reconsideration of retransplantation. Although lung transplantation represents the only life-saving therapy for patients with end-stage lung disease, it has not yet achieved the long-term graft survival results observed with other solid organs. The aggregate international experience reported in the International Society for Heart and Lung Transplantation (ISHLT) Registry ${ }^{1}$ reveals a 5 -year survival for first-time lung transplantation in the range of 50\%. In comparison, the 5-year graft survival for kidney transplantation is $70 \%$, for liver $67 \%$, and for heart $71 \%{ }^{2}$ The primary cause of death after lung transplantation is chronic graft dysfunction or bronchiolitis obliterans, and retransplantation remains the only treatment option for these individuals today. Given the magnitude of late graft failure, it is inevitable that some patients will be back in line, requiring retransplantation.

Retransplantation of the lung has been undertaken by various transplant centers worldwide. It is clear that a retransplant is a higher risk procedure than a first-time transplant and the outcomes have generally not been as good. The Organ Procurement and Transplantation Network reports that retransplantation accounts for about $4 \%$ of the current lung transplant activity to date. The 1-year survival in this group is 59\% and the 5-year survival is 32\% (compared with $79 \%$ and $45 \%$ for 1 - and 5 -year survivals, respectively, for primary lung transplants in that registry ${ }^{2}$ [Table 1]).

When retransplantation is being considered, a number of factors need to be taken into account. These include the timing and indication for retransplant, the presence of other comorbidities, immunosuppressive management, infection prophylaxis, and, importantly, the likelihood of success.

Although no single center has a large experience, a number of recurring trends are seen to emerge from the available single-center case series reports and especially from the analysis of the aggregate international experience. In an analysis of the ISHLT Pulmonary Retransplant Registry, the significant factors favoring survival after retransplantation were: retransplantation after 1991 (era effect), retransplantation in nonventilated patients, greater retransplant interval $(>2$ years since primary transplant), and center experience ( $>5$ retransplants). ${ }^{3}$

The report from the Hannover Lung Transplant group ${ }^{4}$ in this issue of the Journal represents the largest single-center series reported to date and has reaffirmed some of the previously noted factors that influence outcome in lung retransplantation. Most important, the authors have clearly identified a group of patients for whom retransplantation has an equivalent outcome to a first-time transplant, with an impressive 5-year survival of $63 \%$ in patients undergoing retransplantation for bronchiolitis obliterans in their experience.

Retransplantation of the lung has indeed come of age. As experience has been accumulated in lung transplantation in general and also in retransplantation, reports from experienced lung transplant centers, such as that reported in this issue of the Journal, are helping to further define those patients who may benefit most from this therapy. There are many challenges to be addressed, however. It is evident that stable patients with late graft failure from bronchiolitis obliterans syndrome are the best group to be considered for retransplantation. Patients supported by a ventilator and those with poor functional status are high-risk candidates. The Hannover group has reaffirmed that retransplantation for acute primary graft failure or airway dehiscence remains a very high-risk endeavor. It should be noted that even though 
TABLE 1. The Organ Procurement and Transplantation Network graft survivals (Kaplan-Meier) for transplants performed from 1995 to 2002 in the United States ${ }^{2}$

\begin{tabular}{lccccc}
\hline & \multicolumn{2}{c}{ 1 Year } & & \multicolumn{2}{c}{ 5 Year } \\
\cline { 2 - 3 } \cline { 5 - 6 } & $\begin{array}{c}\text { Primary } \\
(\%)\end{array}$ & $\begin{array}{c}\text { Retransplant } \\
(\%)\end{array}$ & & $\begin{array}{c}\text { Primary } \\
(\%)\end{array}$ & $\begin{array}{c}\text { Retransplant } \\
(\%)\end{array}$ \\
\hline Kidney & 91 & 89 & & 70 & 65 \\
Liver & 82 & 63 & & 67 & 43 \\
Heart & 86 & 78 & & 71 & 56 \\
Lung & 79 & 59 & & 45 & 32 \\
\hline
\end{tabular}

these are high-risk patients, experienced centers have on occasion taken on highly selected patients and successfully performed retransplantation.

We need to strive to the point where the outcome for retransplantation is equivalent to that for first-time transplantation, a degree of success that is enjoyed by recipients of second-time kidney transplants. ${ }^{2}$ We need to continue to refine patient selection. This can be done only by continuing to treat patients with retransplantation, but with careful documentation and reporting of outcomes to established databases such as the ISHLT Registry. Careful analysis of the aggregate experience will continue to enlighten us about optimal patient selection, as the Hannover group has done.

Many areas need to be studied further: Is the optimal retransplant operation a single or bilateral lung transplant? Should the primary graft always be removed to avoid leaving a source of infection and inflammation behind, or is a simpler contralateral implantation of a single lung more desirable? Immunosuppressive strategies need to be optimized: Should these patients receive induction immunosuppression because they are at high risk, having had an unsuccessful first transplant, or should they not have any augmentation of immunosuppression because they are already chronically immunosuppressed? Both practices have their potential merits and disadvantages. Further clarification of the role of HLA antibodies is required. The contribution of the presensitized state and humoral mediated immunity is just emerging in lung transplantation, and it is anticipated that this will play a more significant role in retransplantation. The most common cause of death after retransplantation is infection, and immunosuppressive strategies will have to be tailored hand-in-hand with infection prophylaxis and treatment strategies in these patients.

The most difficult question to address is the issue of organ allocation. In the United Network for Organ Sharing lung allocation score, ${ }^{5}$ retransplant candidates are currently listed in group D. The lung allocation score was designed to address wait list mortality and also to take into account the likelihood of a successful outcome after transplant, but the number of retransplants available in the database was too small to effectively model outcome.
As more experience is gained, more data are collected, and better modeling of outcomes is achieved, this will likely change. However, at this time retransplant candidates are not listed differently from those on the list for a first-time transplant.

Since sufficient donor organs are not available to treat all patients who might benefit from lung transplantation, we are faced with a new variant of a familiar ethical debate: the utilitarian principle of helping those who will benefit most or the egalitarian principle of providing equal opportunity to all. ${ }^{6}$

In the past, the outcome data showed that first-time transplants had nearly double the 5-year survival of retransplants. With the use of a utilitarian calculus, retransplant patients were ranked below those who would benefit the most. A second line of moral reasoning, the egalitarian argument, held that those in need should have an equal opportunity to receive a critically scarce resource. This led to the conclusion that individuals in need of retransplantation should be required to wait until others have had their chance at a first transplant. In an earlier era, Collins and Mozdzierz $^{7}$ even argued that cardiac retransplantation should not be permitted at all, on the basis of poor outcomes, fairness to first-time candidates, and maximizing the benefit derivable from a scarce resource. ${ }^{7}$

The Hannover group, through skillful selection and management, has disturbed the ethical status quo. They have clearly defined an appreciable number of lung retransplant candidates who can be expected to have an equivalent long-term outcome to first-time transplants, refuting the utilitarian argument against retransplantation of the lung. The egalitarian argument remains intact: first-time candidates can justifiably claim priority over those who have had their first fair chance. How should we resolve this issue in a practical way?

Considering the responsibility of the medical community to use the limited organs that are available most effectively, the transplant physicians' responsibility to and advocacy for their patients, and the ethical responsibilities of the transplant programs, Mentzer and colleagues ${ }^{8}$ have proposed that a defined percentage of available organs should be allocated for retransplantation. This appears to be a very reasonable path to take at this juncture. Lung retransplantation has evolved from being prohibitively risky to now approaching similar risk to first-time transplants in selected patients. This has occurred only because experienced transplant centers have continued to retransplant, to innovate, and to report on their results-all very important responsibilities of a transplant program. This progress can continue only if retransplantation continues, so that we can further clarify the ultimate role and potential benefit of retransplantation of the lung. 


\section{Conclusion}

Retransplantation of the lung has come of age. The number of patients requiring a retransplant is increasing and the likelihood of a successful outcome after retransplantation is improving. We are faced with a number of challenges to be addressed. Clearly, our first responsibility is to improve outcomes of first-time transplants so that retransplantation should not have to be a consideration. Priority areas of research include causes of primary graft dysfunction and chronic graft dysfunction or bronchiolitis obliterans. Second, we need to optimize the use of donor lungs to make more lungs available. When donor organs become less scarce, the debate about the fairness of retransplantation when others are awaiting a first transplant will become less of an issue. Through innovation and continued attempts to improve outcomes, leading transplant programs will continue to push the envelope to make retransplantation as successful as primary transplantation of the lung.

\section{References}

1. Trulock EP, Edwards LB, Taylor DO, Boucek MM, Keck BM, Hertz MI. Registry of the International Society for Heart and Lung Transplantation: twenty-second official lung and heart-lung transplant report-2005. J Heart Lung Transplant. 2005;24:956-67.

2. Available from: http//www.optn.org/latestdata.

3. Novick RJ, Stitt LW, Al Kattan K, Klepetko W, Schaefers HJ, Duchatelle JP, et al, for the Pulmonary Retransplant Registry. Pulmonary retransplantation: predictors of graft function and survival in $230 \mathrm{pa}-$ tients. Ann Thorac Surg. 1998;65:227-34

4. Strueber M, Fischer S, Gottlieb J, Simon A, Goerler H, Gohrbandt B, et al. Long-term outcome after pulmonary retransplantation. $J$ Thorac Cardiovasc Surg. 2006;132:407-12.

5. Source: www.UNOS.org (Lung Allocation Score [LAS] Calculator).

6. Ubel PA, Arnold RM, Caplan AL. Rationing failure: the ethical lessons of the retransplantation of scarce vital organs. JAMA. 1993;270(20): 2469-70.

7. Collins EG, Mozdzierz GJ. Cardiac retransplantation: determining limits. Heart Lung. 1993;22:206-12.

8. Mentzer SJ, Reilly JJ, Caplan AL, Sugarbaker DJ. Ethical considerations in lung retransplantation. J Heart Lung Transplant. 1994;13: $56-8$.

\section{ON THE MOVE?}

Don't miss a single issue of the journal! To ensure prompt service when you change your address, please photocopy and complete the form below.

Please send your change of address notification at least six weeks before your move to ensure continued service. We regret we cannot guarantee replacement of issues missed due to late notification.

\section{JOURNAL TITLE:}

Fill in the title of the journal here.

\section{OLD ADDRESS:}

Affix the address label from a recent issue of the journal here.

\section{NEW ADDRESS:}

Clearly print your new address here.

Name

Address

City/State/ZIP
COPY AND MAIL THIS FORM TO:

Elsevier Inc.

Subscription Customer Service

6277 Sea Harbor Dr

Orlando, FL 32887
OR FAX TO:

407-363-9661

OR E-mail:

elspcs@elsevier.com
OR PHONE:

800-654-2452

Outside the U.S., call

407-345-4000 